\title{
Style Guide for History in Africa
}

History in Africa - A Journal of Debates, Methods, and Source Analysis (HiA) is published annually by the African Studies Association. HiA is an international, peer-reviewed academic journal that publishes original research and review essays on methodological and historiographical matters pertaining to African history. It has been at the forefront of critical discussion of these topics for more than four decades. It seeks submissions that suggest new methodological approaches, provide insights into source materials, and reflect critically on themes in existing literatures or emerging fields of inquiry. $\mathrm{HiA}$ is a venue for rigorous analysis of both established and emerging research practices as well as of the resulting scholarly production about the African past.

This style guide is intended to standardize important elements of style and thus to aid authors, editors, and proofreaders in preparing copy for publication in the HiA. The details of the HiA style specified here in part codify past practices and in part represent changes from them. For matters of style not included here, consult the reference list at the end of this style guide for additional sources of information. In case of doubt, remember that it is especially important to achieve internal consistency.

HiA does not pay authors for their manuscripts, nor does it provide retyping, drawing or mounting of illustrations, or other such services. Those are the responsibility of the author. The editor reserves the right to reject or return for revision any material submitted on the grounds of inappropriate subject matter, quality, or because of nonconformity with this style guide.

Authors must recognize that they (and not the African Studies Association, nor the editors of HiA, nor Cambridge University Press) are responsible for the content of their articles, for the accuracy of quotations and their correct attribution, for the legal right to publish any material submitted, for the inclusion of mandatory acknowledgments and/or disclaimers, and for submitting their manuscripts in proper form for publication.

A manuscript submitted to HiA may not be under simultaneous consideration by any other journal or have been published elsewhere.

History in Africa, Volume 45 (2018), pp. 491-497

(C) African Studies Association, 2018

doi:10.1017/hia.2018.24 


\section{Submission Guidelines}

SUBMISSION Manuscripts should be sent electronically to Jan Jansen, the managing editor of HiA, at jansenj@fsw.leidenuniv.nl . Acknowledgment of receipt of a manuscript does not imply its acceptance.

EVALUATION Manuscripts are generally evaluated by two anonymous peer reviewers. The editors can normally complete an evaluation of a manuscript in about three to four months depending on the availability and responsiveness of external peer reviewers. Authors are notified as soon as a decision has been made to accept or reject a manuscript. Some rejections are made with the invitation to revise and resubmit, but a new evaluation of the revised manuscript will ordinarily be made.

\section{Preparing the Manuscript}

Manuscripts must be double-spaced throughout, including references, notes, tables, figure captions, and quotations. Margins throughout the manuscript (top, bottom, and both sides) must be at least 1 inch (2.5 centimeters).

Please include as separate sections and in the following order:

- title page with complete title, author name(s) and affiliation(s), a current mailing address, phone number, and e-mail address

- any acknowledgments you wish to make

- a statement that this manuscript has not been previously published nor under review for publication elsewhere

- a bio-sketch (50-100 words) that identifies your affiliation and most important research accomplishments

- a short abstract (50-100 words) that summarizes the essential points of the paper (it is not meant to be an introduction or a mere list of topics). The title of the paper (but not the author's name) should be repeated just before the text of the abstract.

- text (with references in footnotes)

- references (repeated from the footnotes but with author's last name first!)

- figure captions (each on a separate page)

- tables or figures (each on a separate page)

All pages of the manuscript should be numbered consecutively. The manuscript will be sent to external peer reviewers, whose identities will not be made known to the author. Reciprocally, the editors do not reveal to the reviewers the identity of the author(s) of the manuscript. As standard practice, the editors remove the title page before sending it out on review. The author should take care that subsequent pages do not reveal her or his identity.

\section{Textual Elements}

PARAGRAPHS Indent the first line of paragraphs following a hard return. 
SPELLING Use "American English." In all quotations and titles of books, articles, and so forth, the actual spelling in the original is used. When abbreviations are used, they carry periods: i.e., e.g., except for the most familiar acronyms, such as BC and UNESCO. (The first two abbreviations-i.e., e.g.- - are acceptable only within parentheses; write out the words in the body of the sentence.) All acronyms must be spelled out when introduced in the text and placed in parentheses, for example, African Studies Association (ASA).

TEXTUAL EMPHASIS The only forms of textual emphasis used in HiA production are italics and bolding. Please do not format any text by underlining.

ITALICS Words in languages other than English and French are always italicized; use standard orthographies, including diacritical marks and accents, and explain unusual symbols. Titles of books, journals, poems, and other literary works are italicized when mentioned in the text; article titles are in roman type, set off by quotation marks. Foreign words and phrases in common usage (and found in an English dictionary) should not be in italics. A word considered as a word is italicized (e.g., "The word knowingly functions as a loophole in the law").

BOLDING is used only in the following contexts:

- the title of the essay

- the word Abstract that precedes the abstract text

- section headings

HEADINGS If you wish to divide your article into sections, section headings must be used. Do not use numbers, as these are not part of the HiA style.

NUMBERS Numbers from one to one hundred are spelled out in the text, unless part of an enumeration that contains a number larger than one hundred ("67 infants, 114 children, and 50 adults"), in an arithmetical expression ("a frequency of 1 in 18"), or in a vote ("the bill passed, 76-69"). Numbers from 101 upward are written as numerals, except for round numbers: three hundred, fifteen hundred, six thousand. Percentages are expressed in figures, with the word spelled out (98 percent). In reference to parts of books, numerals are spelled out ("chapter 6"). Century designations are spelled out: "seventeenth century," "nineteenth-century labor practices." A decade is referred to as "the 1960s" (not "the 1960's"). When pages are cited, digits are never elided. A span of years cited within a single century should appear as "1978-1979" not "1978-79." Render dates as, e.g., 26 March 1938 ("continental dating”). Inclusive numbers or a span of numbers in a date (6-8 June) are separated by a one-en dash, not a hyphen. Ordinal numbers, where necessary, should not be written in superscript (14th, not $14^{\text {th }}$; also, 2 nd, not $\left.2^{\text {nd }}\right)$. Hours of the day are written as 2:00 A.M., 6:00 P.M., with the letters in small caps. 
PUNCTUATION Use American-style punctuation: double quotation marks (but single quotation marks for quotes within quotes), periods and commas inside quotation marks, colons and semi-colons outside quotation marks. HiA does use the serial comma ("There were three children, thirteen adults, and six pets.”) A parenthetic dash should appear as a one-em dash (rather than as two hyphens).

QUOTATIONS Direct quotations exceeding four manuscript lines of type should be set off from the text by indenting the entire quotation one stop from the left. No further indentation is necessary for the first quoted paragraph; the first line of subsequent paragraphs in the same quotation should have an additional paragraph indent. Remember that quotations must be double-spaced. Material added by the author of the article within the quoted portion should be enclosed in brackets, not in parentheses. (However, minor syntactical changes do not require brackets around a single letter, as with an initial capitalization.) Added emphasis should be identified as "emphasis added" and placed in brackets at the end of the quotation. Omissions in a quotation are indicated by using (...)

NOTES All notes should be formatted as footnotes. Notes are restricted to references and to material that cannot be conveniently included in the text. Note numbers should appear at the end, not in the middle, of the sentence and should never be attached to display material (the title or subheadings).

REFERENCES $A l l$ references cited in footnotes must appear in a References section at the end of the article, and all entries in References must be cited in the text. The only exception to this rule is the use of personal communications (please see sample in the following section for guidelines).

Alphabetize the reference list by last names of authors. Two or more works by the same author or authors should be listed chronologically, the oldest first; two or more by the same author or authors in the same year should be alphabetized by the first significant word in the title.

Special care should be taken with references to ensure that recommended punctuation, form, and so forth, are used to ensure a minimum of delay and expense in the publication of articles in the HiA.

Authors are responsible for the accuracy and completeness of their reference lists. See sample reference list below.

SAMPLE REFERENCES The following are examples of how references should look in a manuscript.

1. Book, single author.

Ainsworth, Mary D.S., Infancy in Uganda (Baltimore MD: Johns Hopkins University Press, 1967). 
Note. Full first name(s) of author(s) should be included if possible. If a publisher has offices in two cities, only the first city named in the book should be included.

2. Book, multiple authors.

Hammond, Dorothy, and Alta Jablow, The Africa That Never Was: Four Centuries of British Writing About Africa (Prospect Heights IL: Waveland Press, 1992).

Note. Place only the first author's name in reverse order. For name of publisher, do not include "and Company," "Inc.," "Publishers," "Publishing Company," and so forth. If the city is not well known, include state name or country with place of publication unless the location is clear from the name of the publisher (e.g., a state university press). For obscure publications still in print, provide address (pamphlets, etc.).

3. Books, etc., single or multiple authors, more than one entry.

Mudimbe, Victor Y., The Invention of Africa: Gnosis, Philosophy and the Order of Knowledge (Bloomington IN: Indiana University Press, 1988).

Parables and Fables: Exegesis, Textuality, and Politics in Central Africa (Madison WI: University of Wisconsin Press, 1991).

Note. A three-em dash followed by a period takes the place of the author's name in the second entry.

4. Edited book, listed by editor(s).

Douglas, Mary, and Phyllis Kaberry (eds.), Man in Africa (Garden City NY: Anchor Books, 1971).

5. Article in edited book.

Werbner, Richard, "Introduction: Multiple Identities, Plural Arenas," in: Richard Werbner and Terence Ranger (eds.) Postcolonial Identities in Africa (London: Zed Books, 1996), 1-28.

Note. Full first name(s) of editor(s) should be included if possible.

6. Book, no author, government publication.

U.S Government Printing Office, Style Manual (Washington DC: U.S Government Printing Office, 1997). 
7. Monograph.

Stroeken, Koen, Moral Power - The Magic of Witchcraft (Berghahn Books: New York, 2010).

Note: when published in a series, don't mention this.

8. Dissertation.

Ciekawy, Diane Marie, "Witchcraft Eradication as Political Process in Kilifi District, Kenya, 1955-1988," PhD dissertation, Columbia University (New York, 1992).

9. Article in journal.

Geschiere, Peter, "Sorcery and the State: Popular Modes of Political Action among the Maka," Critique of Anthropology 8-1 (1988), 35-63.

Note. If each issue of a journal begins with page 1 , the issue number should be included, following the volume number. Avoid Roman numerals.

Note. Treat a text from an e-journal as an article in journal, and add the website's name.

10. Unpublished manuscript.

Munroe, Ruth H., and Robert L. Munroe, "Quantified Descriptive Data on Infant Care in an East African Society," Department of Psychology, University of Zambia (Lusaka, unpublished manuscript, 1971).

Note. Include location and date of composition of unpublished manuscripts whenever possible. If the date is unavailable, the letters "n.d." should replace the date shown above and should be used in the in-text reference.

11. Paper presented at meeting.

Onuegeogwu, M., "Urbanization in the Kano Close Settlement Zone," paper presented at the 7th Annual Meeting of the Nigerian Sociological and Anthropological Association, Ibadan, 15-19 November 1978.

12. Internet publication.

Find the author of the text, and treat it as an article in journal, and add website's address plus date of access, for instance: (accessed 3 February 2011). If there is no author, be cautious with using the information. 
13. Personal communications.

Letters, phone calls, e-mails or other personal forms of communication with the author should be cited in the text but not in the References section. In text they should appear as: Jeff Kaufmann (personal communication, 21 August 2011). Make the date as complete as possible. 